\title{
Destructive Leadership: From Retrospective to Prospective Inquiry (Antecedents of Destructive Leadership)
}

\author{
Tarık ATAN \\ Cyprus International University, Lefkosa, TRNC \\ tatan@ciu.edu.tr
}

\begin{abstract}
This article explores the concept of destructive leadership and looks at potential ways of anticipating it in advance. To achieve this, the article considers the concept of leadership and especially the "leader-manager" dilemma as a lens to clarify the contextual processes that encourage the emergence and growth of destructive leadership. The article, then, focuses on how destructive behaviors proliferate and become part of organizational structures and how followers can disseminate the effects of these behaviors. In this regard, it sheds light on profoundly catastrophic consequences for the leader, the organization, and humanity at large because of destructive leadership.
\end{abstract}

\section{LEADERSHIP AND MANAGEMENT}

With over 2,000 books and 1,000 articles written annually about leadership, each with a different perspective, one could easily claim that the topic has been comprehensively analyzed and is therefore truly understood. However, leadership remains a highly ambiguous and elusive subject. Neither an agreed definition nor a conceptual basis for the professional language and terminology exist (e.g., [1]; [2]; [3]; [4]).

While clarifying the concept, it is a common approach to differentiate management and leadership. This serves as a useful tool, a "lens" through which an understanding of the perspective can be constructed, and which in turn could prove very useful in discussions about destructiveness and destructive leadership. This approach, which differentiates management and leadership as intrinsically different, also emphasizes their togetherness. Kotter [5] accentuates the necessity of them existing together although they are different constructs. Zaleznik [6] describes them as two distinctive systems of action, each with its own functions and characteristics. In this regard, both are essential for success in an increasingly complex and insecure environment, and complement each other. By viewing the two concepts in a domain analysis, three distinct areas can be made visible: "management," "leadership," and "management-leadership". It should be emphasized that the borders between these "states" are blurred and ambiguous.

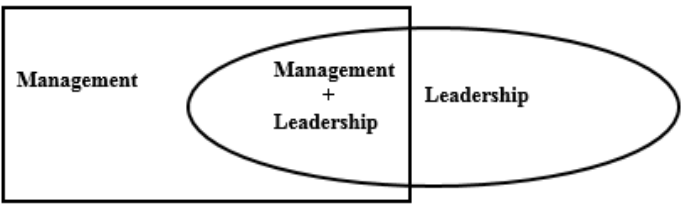

Figure 1: An illustration of the areas representing "management", "leadership," and "management + leadership" as intersections 
Researchers seem to agree that the basic concept that differentiates leadership from management is change. Leadership is constructed around change while management is constructed around stability. Change, which in this instance is not gradual but sudden and drastic, reflects Miller's [7] "quantum view of change" and Tichy's [8] "strategic change." The latter is "non-routine, non-incremental, and discontinuous change which alters the structure and overall orientation" [8].

Barker [9] develops this issue of leadership and sudden change by emphasizing "crises" and not a "kaizen" type of incremental change, stating: "Leadership, must necessarily be founded in crisis. It is crisis that acts as a catalyst for the leadership process. For this purpose, crises can be defined as a perceived differential between what exists in the social order and what is desired" [9]. This perspective matches Schumpeter's [10] description of crises in his study Creative Destruction, which highlights the wholesale transfer of a system from one norm to another in a process that is indivisible. He implies that the process is "an attempt by the firm to keep on [its] feet, on the ground that is slipping away, therefore instead of administering relevant structures, the relevant problem ... [is] how to destroy and re-create." Marion and UhlBien [4] describe this as "the nonlinear characteristic of complex systems" and emphasize the slow building of aggregates and meta-aggregates until at some point

\footnotetext{
"a critical mass occurs, emergence accelerates and major change becomes inevitable, and very shortly following that, the pieces come together precipitously, as if overnight. Thus an innovation seems to appear out of nowhere, but of course much construction occurs behind the scenes before the pieces fall into place, and the change only seems to be precipitous."
}

Such references to crises appear to allude to major problems in the context of leadership. However, we believe that the term "crises" should also cover minor problems because any change that requires a paradigm shift involves leadership. For example, leadership has been advocated as a solution to personal, social, and organizational problems. Further, some problems are ambiguous, and as such often have a political element that is fertile ground for leadership [11]. The simple perception of a "crisis" could also be enough to create leadership dynamics.

Notably, this perspective does not see leadership as the creator of change; instead, it regards change as the creator of leadership. "Leaders are part of a dynamic, rather than being the dynamic itself" [4]. Therefore, leadership is labeled as the legitimate offspring of conflict, a term that could be synonymous with "crisis." Alternatively, reverse causality could be true as well. Leadership can and must create and initiate change, while change can and will create leadership. Hence, leader-managers who act at the intersecting area of the domain analysis embrace change and even initiate change while retaining control and assuring controlled, smooth, and efficient change [5].

The middle ground, where management and leadership exist together, as illustrated in Figure 2, has been described as the area essential for the healthy existence of an organization [5] where both are needed for a well-functioning organization, while warning of the potential conflict between these roles. Kotter's [5] brilliant analysis on the management-leadership dyad provides a clear description of the boundaries of the middle ground of the management-leader intersection:

“... leadership by itself never keeps an operation on time and on budget year after year. And management by itself never creates significant useful change. Taken together, all of these differences in function and form create the potential for conflict. Strong leadership, for example, can disrupt an orderly planning system and undermine the management hierarchy, while strong management can discourage the risk taking and enthusiasm needed for leadership." 
Kotter [5] refers here to "risk-taking," a concept that Scherr and Jensen [12] also consider when they postulate a difference between leadership and management based on perspectives of risk. They argue that management is about minimizing risk and maximizing predictability, while leadership deals with the risk and uncertainty of change.

Bearing in mind the dynamic nature of the movements between the domains, a manager with official power is also the best candidate for leadership. Therefore, one should expect that managers easily become "leader-managers" (see Figure 2). Similarly, an emergent leader who proves to have sufficient courage, competencies, capabilities, and/or expertise should and, in most cases, will also assume the official role of the manager together with the title.

Figure 2: An illustration of the movements to the intersecting area to become "manager + leader"

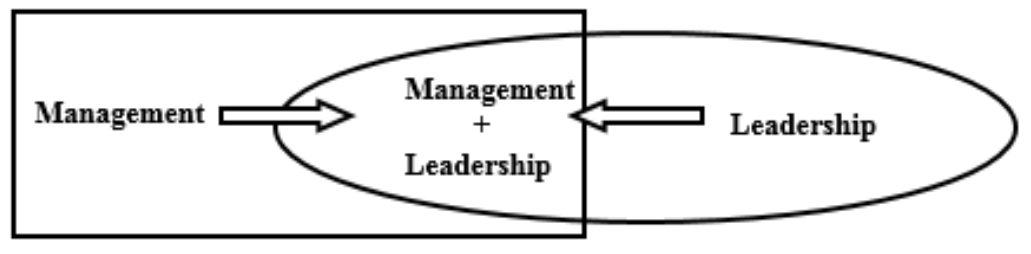

\section{ON DESTRUCTIVE LEADERSHIP}

Despite the significant aforementioned interest in leadership, academic research has paid little attention to the topic of destructive leadership until recently. In general, destructive leadership has been seen as synonymous with "lack of leadership," and a more definitive description of "destruction" has not emerged. Perspective, time scale, and context all appear to have a strong influence on the idea of "destruction." However, should we describe a destructive leader by focusing on situational factors, processes, or end results? If the latter, will short- or long-term results be negatively correlated, as is commonly the case? Should we look to purposes and intents, or means? To whom is leadership destructive if the outcome favors one stakeholder and damages others? What is the role of situational factors and, of course, the chance factor? Does the legality of leadership, or the lack of it, affect destructiveness?

Kellerman [13] accepts that there are no easy answers to these questions. Padilla et al. [14] state that the test of destructive leadership (which they also refer to as "toxic leadership") is a matter of outcomes and should be evaluated in terms of negative organizational outcomes. In this context, they conclude that certain processes are more likely than others to lead to such outcomes.

Einarsen et al. [15] cite some of the concepts that fall within the domain of destructive leadership as follows: "abusive supervisors" [16], [17]; "health-endangering leaders" [18]; "petty tyrants" [19]; "bullies" [20]; "derailed leaders" [21]; "intolerable bosses" [22]; "psychopaths" [23]; and "harassing leaders" [24]. Destructive actions directed against the organization have also been identified (e.g., working toward goals other than those defined by the organization), examples being Lipman-Blumen's [25] concept of "toxic leaders" and McCall \& Lombardo's [26] concept of leader derailment.

Further destructive leadership behavior includes personal insults, uninvited physical contact, threats and intimidation, humiliation, public shaming or status degradation rituals, impolite interruptions, and treating people as if they were invisible.

Shewchuk [27] provides a long list of "destructive boss behaviors" and includes rudeness, yelling at staff, being partially or wholly deceitful, humiliating and intimidating staff, being sarcastic, swearing, and using inappropriate humor. Such behavior also comprises arrogance, giving negative feedback, withholding recognition, slamming doors, being excessively angry, 
withholding information, micromanaging, taking credit for work done by others, frequently reminding everyone who is in control, and exuding a supervisory "above-it-all" attitude. Further, Shewchuk [27] mentions racism and sexism as "toxicity makers" related to bullying. In this context, it is worth noting Yukl's [28] comment that the hostility this behavior evokes among staff influences leader effectiveness. The indicators of such hostility toward a leader include "absenteeism, voluntary turnover, grievances, complaints to higher management, requests for transfer, work slowdowns, and deliberate sabotage of equipment and facilities" [28].

In her comprehensive study Bad Leadership, Kellerman [29] divides the subject of destructive leadership into two broad categories, ineffective and unethical leadership. She emphasizes that the borderline between the two may never be adequately defined, and proposes a seven-item typology to describe bad leadership: incompetence, rigidity, intemperateness, callousness, insularity, corruptness, and evil.

Einarsen et al. [15] focus on the harm inflicted by destructive leadership on an organization and its workers, and define such leadership as

"The systematic and repeated behavior by a leader, supervisor or manager that violates the legitimate interests of the organization by:

a) Undermining and/or sabotaging the organization's goals, tasks, resources, and

b) Undermining the effectiveness and/or the motivation, well-being or job satisfaction of his/her subordinates."

They further classify destructive leadership behaviors in three categories: tyrannical, derailed, and supportive-disloyal behaviors. These are an innovative extension of Blake and Mouton's "managerial grid" [30].

Padilla et al. [15] describe destructiveness in relation to long-term outcomes and define it with reference to its principle direction or target: either toward the self (personal destructiveness) or toward the organization, its internal membership, and external stakeholders.

Illies and Reiter-Palmon [31] suggest that destructive behavior harms organizational members or strives for short-term gains instead of long-term organizational goals. In their study, they cite O'Connor et al. [32] who define a destructive leader as an individual whose decisions "clearly harmed his or her society or organization."

Schaubroeck et al. [33] concentrate on aspects of leadership and conclude that an

"Emotionally unstable supervisor is a potential source of distress that is constant and cannot be resolved by using active (i.e., problem-focused) coping strategies. Subordinates are rarely in a position to exert problem-focused coping to overcome difficulties they experience in interacting with a hostile supervisor. Such a chronic source of distress over which subordinates have no control, be it in the form of feeling belittled by the supervisor's contempt, frustration, blaming, intimidation, excessive control, unrealistic expectations, or just poor communication, may be expected to create anxiety, somatic complaints, and general dissatisfaction. Ultimately, this may reduce their psychological commitment to and desire to stay employed by the organization."

In sum, we may attempt to classify leadership destruction by using three broad categories:

- $\quad$ destruction to self;

- $\quad$ destruction to an organization, peers, and subordinates; and

- destruction to humankind in general. 
We can see one or more, and in most instances all three, outcomes in many examples of destructive leadership. In the widely covered Enron case, the corporation collapsed, a situation that left stakeholders out in the cold; caused the loss of a great deal of wealth for society; and greatly damaged the image of business. An even more extreme example is that of Hitler. He eventually committed suicide in a bunker, leaving behind a devastated country and more than 20 million dead.

Illies and Reiter-Palmon [31] cite Mumford et al.'s [34] composite measure that has three belief-based constructs: (a) power motives, (b) myth viability (having a destructive image of the world), and (c) object belief (the belief that one can use others for personal gain). They contend that individuals who score high in each of these dimensions can be defined as destructive. Mumford et al.'s [34] findings revealed that individuals with high scores made more destructive organizational decisions (hurting long-term goals or profitability) and interpersonal decisions (harming organizational members) when they had either the support of an authority figure or low self-efficacy. Therefore, although there is a considerable volume of valuable research, especially in psychology and social psychology, we are more inclined to look at the organizational and situational perspectives of leadership that produce destructive behaviors, or at least provide fertile ground for destructive decision-making, rather than the individual and/or psychosocial characteristics of destructive leaders.

\section{ANTECEDENTS OF DESTRUCTIVE LEADERSHIP}

Using the management-leadership dilemma as a "lens," leadership is the ability to see the big picture and to be able to envision and thus embrace change. A lack or deterioration of these abilities constitutes destructiveness. Indeed, the "vision" can make a significant difference for organizations, distinguishing them from mediocre and reactive organizations. Therefore, lack of vision can mean falling behind and eventual destruction. However, the questions remain of who defines vision, what happens if change requires a new vision, and whether the "visionary leader is capable of discarding the old one] and adopting the new right 'vision'." It is known that "visionary leaders" have the habit of "going over the edge" [35]. Visionary leaders are expected to "see" the future state of the organization and enable others to see it as well. They are meant to be exceptional speakers, using language in symbolic forms as metaphors, and must attract, impress, and influence people. However, this is exactly what Hitler did. Therefore, from this perspective, the existence of "vision," rather than reducing risk, could actually increase it [35].

As aforementioned in the domain analysis, there are three states: "management," "management + leadership," and "leadership." However, the dynamism that is indicated by the movements among these three domains can clarify the perspective as follows.

a) Management and movement from management to management-leadership.

b) Leadership and movement from leadership to management-leadership.

c) Failing to stay in the management-leadership domain.

These processes are now considered in more detail.

\section{a) Management and movement from management to management-leadership}

Beginning with Fayol [36], the task of management has been widely researched and explained. A general categorization of planning, organizing, leading (within the context Fayol implied) and controlling are widely accepted as the basic tasks of management [37]. Therefore, failing in one or more of these functions negatively affects the organization. This can be either a slow, painful process or a drastic, sudden blow. Generally, such a failure in management originates from the appointment of an inadequate candidate to an official position. This can happen in almost any 
organization but the most dramatic examples are visible in governmental organizations. Political pressures, and more commonly ideological biases, force administrators to appoint managers not on their competencies and capabilities, or even by tenure, but on a "one of us" approach. A manager who lacks the necessary skills to conduct management tasks and is appointed to his post in this way can do nothing but rely on bullying and intimidation to exert power and assure acceptance [38].

The incompetency of the manager will be visible at once to peers and followers, and trust and respect is certain to evaporate. Negative build-up is continuous; the manager will be forced to exert greater personal control and will become less able to hear the counsel of advisors or staff members who might be helpful. Of the supposed "followers," those who resist will leave the organization voluntarily or by force. In the worst case, the organization's resources are exhausted and the company fails.

Another common failure pointed out by Ferris [39] is that of managers who rise to positions of power only by possessing task-specific skills and are not able to recognize the power of subordinates. This inability to recognize such power releases them from normal self-imposed constraints and allows them to pursue power and reputation via their legitimate position in the organization. This is another direct route to destructive tendencies. Mintzberg [35; 40] refers to the power of subordinates embedded in the concept of organizational culture and highlights the risk as follows.

\begin{abstract}
"Culture encourages the production of unique outcomes and it is loaded with causal ambiguity, which makes it difficult to understand. An organization's inability to understand and reproduce its own culture may be the best guarantee of its strategic advantage - far better than any security system or legal device ever devised. So, for example, an insider who leaves cannot necessarily replicate a resource for a competitor. But paradoxically that also renders it vulnerable, easily destroyed by any leader who makes dramatic moves without being able to assess their impact on the organization) [35]... Therefore ... while culture itself may be difficult to build in the first place, and even more difficult to reconstruct later, it is rather easy to destroy. Give some disconnected "professional" manager enough authority, and watch what happens." [40]
\end{abstract}

On the other hand, a manager holding official power, even when extremely successful in dealing with motivation and other human issues, may not be considered a leader until the true measure of leadership, a crisis, arrives. Management usually spends its time dealing with the current situation and has a tendency to acquire a mantle of myopia; therefore, it usually fails to foresee crises. Managers generally do not see changes in the environment until too late. A change becomes increasingly untamed and, at some point, a crisis erupts that threatens the system. Consequently, the organization becomes "unfit" and ends in disarray. In such a situation, either an emergent leader takes over who steers the organization to either safety or doom, or the institutionalized power of the management prevents any internal or external intervention and carries the destruction through to the end.

The Institute for Crisis Management (ICM), cited by James [41], classifies most crises into two groups: "sudden crises" and "smoldering crises." Although our focus is on management crises, which are included in the smoldering crisis category, sudden crises such as technology disruption, natural disasters, terrorist attacks, and sabotage can also test the capability of the manager as a leader. In such situations, a perspective of courage and wisdom is the determining factor in transforming management into the management-leadership sector. History is full of mediocre administrators who otherwise would have remained in obscurity but, when confronted with a crisis, they transformed brilliantly and became great leaders. 
In contrast to these arguments, evidence suggests that some managers are able to foresee trouble and initiate change. Mintzberg et al. [35] formularize this process as follows: "The key to leadership therefore is to sustain stability or at least adoptable strategic change most of the time, but periodically recognize the need for transformation and be able to manage that disruptive process without destroying the organization." From this perspective, managers that face smoldering crises [41] that start in a small way, but have the potential to escalate into a full-blown crisis over time, should be able to detect and initiate the necessary change, thus creating a controlled crisis. For example, Jack Welch was the CEO of General Motors (GM), a massive corporation that was safe, profitable, and effective. He sensed changes in the business environment, however, and believed that the corporation faced imminent disaster. He initiated a massive change process, accepting considerable risk and determined resistance.

\section{b) Leadership and movement from leadership to management-leadership}

When confronted by pressure to conform, a deviant person who is a potential leader is certain to feel isolated and faces a risky and intimidating experience, being at the nexus of constructive and destructive forces. Machiavelli [42] describes this risk:

"There is no more delicate matter to take in hand or many dangerous to conduct, nor more doubtful of success, than to step up as a leader in the introduction of change. For he who innovates will have for his enemies all those who are well off under the existing order of things, and only lukewarm support in those who might be better off under the new."

From this perspective, leadership is closer to entrepreneurship. Both struggle against the status quo, and adopt an "I know better" attitude. The deviant person, after gathering the support of followers (or collaborators), assumes the powers of leadership. However, followers (or collaborators) can align with the wrong person. A psychopath can easily gain power and move toward destruction in an ill-defined and ambiguous situation such as real or perceived threats from followers (or collaborators) and perceived instability [11]. In such circumstances, the potential for leaders to make destructive decisions or follow a destructive course of action is always present [31]. Thus, supporting an emergent leader always carries the risk of taking a shortcut to destruction.

However, if we assume success in resolving a crisis, the risks do not diminish. Usually, an emergent leader who takes command in a crisis and proves to have bravado, as well as competency and capability, quickly gains an official title and official power, thus becoming a leader-manager. In this situation, if he or she is unable to demonstrate necessary management skills, the organization's drift to destruction is still inevitable. According to Conger [43]:

"The very behaviors that (make) leaders ... also have the potential to produce problematic or even disastrous outcomes for their organizations. For example, when a leader's behaviors become exaggerated, lose touch with reality, or become vehicles for purely personal gain, they may harm the leader and the organization. ... Fundamental errors in the leader's perceptions can also lead to a failed vision. Common problems (of lack of management skills) include (1) an inability to detect important changes in markets (e.g., competitive, technological, or consumer needs); (2) a failure to accurately assess and obtain the necessary resources for (success); and (3) a misreading or exaggerated sense of the needs of markets or constituents. The very qualities that distinguish the ... leader contain the potential for disaster."

Greiner's [44] model of "organizational growth" highlights management problems as the first crisis an organization faces after its establishment, and suggests that these have the potential for disaster. Greiner states that "as the organizations grow, the founding entrepreneurs confront the task of having to manage the organization, as they discover that management is a 
very different process from entrepreneurship" (Ironically, Greiner names this type of crisis a "leadership crisis.")

The other issue to consider here is the perspective of followers. They tend to become dependent on the leader, impressed with his or her performance and bravado. Consequently, they ignore any negative aspects and offer unconditional loyalty, and thus, by their own actions, perpetuate the problem of potential disaster. Leaders welcome such total loyalty because they need to dominate and be admired. The resulting sense of omnipotence and invincibility encourages a denial of market and organizational realities. Thus, a successful emergent leader may fail to become a leader-manager. The end of this course is bleak. Leaders' desire for heroic recognition encourages them to undertake large, risky ventures. Warnings, criticisms, and signs of failure only serve to make them more aggressive, short-tempered, and destructive, a situation that often alienates followers, peers, and superiors. Such leaders and their loyal followers will then be cast out of organizations; if not, the organizations suffer the consequences.

\section{c) Failing to stay in the management-leadership domain}

As aforementioned, leadership is a dynamic process; further, a leader-manager is under constant pressure from the forces of change. Therefore, whether they enter the managementleadership domain from the leadership or management side, if leader-managers cannot maintain their positions, they will be under threat.

However, maintaining a leader-manager position is fraught with difficulties. For example, a leader's past successes combined with the followers' acceptance of him or her as a hero blur the fact that the leader may no longer represent the defining values, needs, and realities of the organization and its environment. In this regard, Kellerman [29] comments on the power of leaders as follows:

\footnotetext{
"As leaders buy their own publicity, they begin to rule the organization as if it were their own fiefdom. They believe their own hype and invest in it. They tend to acquire bad habits - to become complacent and grandiose, to overreach, to deny reality, and to lose their moral bearings."
}

Successful leaders may also come to ignore the efforts of their collaborators and followers. For example, Fletcher [45] cites Beer [46] and suggests that because of the nature of identity and ego, leaders who have achieved a goal and gained prominence for this achievement, tend to overlook the help they have received and reconstruct their behavior-in their own minds as well as in the perception of others-as individual action. Fletcher [45] also cites the work of Meindl et al., [47], who propose what they call the "romanticizing" of leadership as an explanation for a related form of social construction. This romanticizing occurs when a series of causally unrelated, ambiguous events are reconstructed in retrospect as intentional action and then described as "leadership." Rosenzweig [48] refers to this as the "halo effect," remarking that the direction of causality is wrong. Many things that are commonly believed as "contributions to company performance" are in fact "attributions." In other words, outcomes can be mistaken for inputs.

It is evident from such arguments that no clear formula can ensure an organization's success. If this were possible, leadership would be obsolete, and there would be no need for managers to move to management-leadership positions. After all, who else but a good manager is capable of ticking the right boxes to ensure that a formula has been followed with the utmost precision? Unfortunately (or, perhaps, most fortunately), organizational leadership and management do not work in this way. A leader-manager who holds official power because of past performance could tend to evaluate each problem that occurs in a familiar rather than flexible way, and worse, followers may back this inclination. Therefore, as already suggested, the very process 
that created the leader-manager may also contain the seeds of destruction. For example, an organization may become increasingly misaligned with the environment; thus, the power of the leader-manager will be threatened. Usually, this threat forces the leader-manager to take measures to institutionalize his or her power, an approach that is relatively easy to take. Such institutionalization carries the threat of force, and since people have a tendency to obey, using force to ensure their compliance is easier than other means. Stout [49] emphasizes this:

\begin{abstract}
"Threat is a powerful motivator which triggers an automatic and immediate response that happens without thinking. This strong preservation instinct is carved into our conscience by millions of years of evolution, exposed to danger. This is why those in an authority position have traditionally found that threats, intimidation, and pressure are much more effective than positive motivators."
\end{abstract}

Hence, in Lord Acton's famous words from 1887: "Power tends to corrupt, and absolute power corrupts absolutely. Great men are almost always bad men." Yukl [28] elaborates further, stating: "The notion that power corrupts is especially relevant for positional power. Throughout history many political leaders with strong positional power have used it to dominate and exploit subordinates."

Salancik and Pfeffer [50] explain this process:

"Because of the processes by which power develops and is used, organizations become both more
aligned and more misaligned with their environments. This contradiction is the most interesting
aspect of organizational power. Because power derives from activities rather than individuals, a
leader's power is never absolute and derives ultimately from the context of the situation. But
power has a capacity for influence that extends far beyond the original bases that created it."

Thus, power is facilitated by voluntary or involuntary conformism. However, more important than this is the fact that "power tends to take on institutionalized forms that enable it to endure well beyond its usefulness to an organization. Those in power will not give up their positions so easily; they will pursue policies that guarantee their continued domination." Salancik and Pfeffer [50] call this the "institutionalizing of power." In their own words:

\footnotetext{
"Current holders of power can structure the organization in ways that institutionalize themselves. By institutionalization, we mean the establishment of relatively permanent structures and policies that favor the influence of a particular subunit. While in power, a dominant coalition has the ability to institute constitutions, rules, procedures, and information systems that limit the potential power of others while continuing their own. The key to institutionalizing power always is to create a device that legitimates one's own authority and diminishes the legitimacy of others"
}

This concept is called "Parkinson's Law." After prolonged and detailed studies on administrative processes in the British Navy, C. Northcote Parkinson argued that growth in the number of managers and hierarchical levels is controlled by two principles: (1) "an official wants to multiply subordinates, not rivals," and (2) "officials make work for one another" [51]. Thus, institutionalized power and fixed structures created by leader-managers will become unquestioned features of an organization, a situation that will eventually be devastating.

\title{
DISSEMINATION AND PROLIFERATION OF DESTRUCTIVE LEADERSHIP
}

Destructive behaviors carry the same perils for an organization as for leaders, whether the behaviors originate from an incapable manager, a manager who fails to become a leadermanager, a psychopath who holds power under pressure and/or who fails to become a leadermanager, and a leader-manager who loses touch with reality but succeeds in institutionalizing her/his power. Such behaviors create a toxic atmosphere that affects everyone. In addition, 
pressures from the environment and the possibility of failure create increasing negativity. Consequently, basic management practices may cease to exist, leaving brute force as the only remaining way to enforce power. Faced with this scenario, followers are inevitably affected. Indeed, over time, it appears that the negative environment created by bullying (and other destructive behaviors) adversely affects motivation and morale to the extent that the focus and quality of production and/or service is significantly disrupted [39]. Ferris et al. [39] also state that

\begin{abstract}
"Workers who experience assertive, tactical bullying are more likely to quit than those who are not bullied, but if they remain at their job, their attitudes toward their jobs will inevitably diminish. Even if the workers show commitment to the company, the way in which the assertive, tactical bullying leader treats these employees will encourage neither respect, nor trust, nor obligation."
\end{abstract}

Moreover, followers actively disseminate destructive behaviors and help create a toxic culture, which has far-reaching effects. People not only evaluate leadership in organizations based on their preconceptions, they also have a tendency to romanticize leadership [52]. This will in turn evoke a "personal identification" by which followers imitate the leader's behaviors and develop similar attitudes [28]. "Isomorphism" [53; 54] is an expression that has been used to explain the similarity of organizations, but it can be borrowed and extended to the management concept of coercive, mimetic, and normative isomorphism among organizations. Isomorphism is coercive when upper management pressures line managers to adopt certain behavior models (i.e., destructive leadership behaviors): it is mimetic when managers intentionally imitate and copy upper management's behavior patterns; and it is normative when these patterns become the organization's culture. Mimetic behaviors may be a nonconscious tool of some sort that individuals may instinctively use, even among strangers and the most minimal of circumstances [55]. Indeed, mimicry may be default, automatic, and unmediated behavior, but we know that it affects postures, mannerisms, moods and emotions [56], and beliefs and judgments, which in turn create what behavioral scientists call "our social guidance system" [57]. Further evidence for the automaticity of mimicry comes from neuroscientific research on mirror neurons [58]. This research shows that within the human brain, there is an intimate link between observing an action and performing the same action oneself. The research finds that the brain is peppered with neurons that mimic, or mirror, what another being does. This previously unknown class of brain cells operates as neural Wi-Fi, allowing us to navigate our social world. When we consciously or unconsciously detect someone else's emotions through their actions, our mirror neurons reproduce these emotions. Collectively, these neurons create an instant sense of shared experience. Such attunement is literally physical. Thus, followers of an effective leader experience rapport with him or her. This is called "resonance" [57]. Spending time with a living, breathing model of (destructive) leadership behavior provides the perfect stimulation for followers' and subordinate managers' mirror neurons, which allow them to directly experience, internalize, and ultimately emulate what they observe. Be it physical and/or psychological, this effect will cause further proliferation of the destructive atmosphere of an organization. "It is the collective system that learns; there are many potential (destructive) leaders in most organizations" [35]. This framework may be characterized as a "trickle-down" model [59]. From the standpoint of this model, the injustices that supervisors experience trickle down (through abusive supervision) to produce injustice and anger reactions among subordinate targets [60]. Further, this chain of mistreatment continues even beyond subordinate victims because targets of severe bullying are likely to take their experiences home where they may displace aggression onto family members $[61 ; 62 ; 63]$. 


\section{CONCLUSION}

It is impossible to deny that bad, or at least unworthy people, often occupy top leadership positions. Capricious, murderous, high-handed, corrupt, and evil leaders are everywhere. In corporations, overweening personal ambition and greed have driven many CEOs to run afoul of the law. In recent years, scores of powerful and successful executives have been indicted for financial wrongdoing of various kinds. As the New York Times wryly quipped, it now "takes a scorecard to keep up with corporate scandals in America" [64].

Negative events in social interactions have a stronger effect than positive events [65]. Destructive leadership is one such negative event and requires much closer attention and research because everyone is familiar with its unwanted and sometimes terrible consequences. Thus, the ability to recognize destructive leadership behaviors, understand the situations and contexts that give birth to these, and understand and prevent the social dynamics that encourage volunteer followers and active collaborators are issues of paramount importance. Mintzberg et al.'s [35] words reflect these issues:

"When should followers stop following, say Hitler, Churchill and Gorbachev? Time and again, it is emphasized that outstanding performance necessitates passionate, singleminded dedication. But when exactly does this dedication pass the line from construction to destruction?"

Mintzberg et al. [35] also cite Miller [7] who refers to the question quoted above as "The Icarus Paradox." Icarus, a mythological figure with perfect flying ability, aims to reach the sun, which, however, melts his wings and sends him to his death. Miller tries to explain this process in terms of "trajectories" where a) the "focusing" trajectory can turn a quality-driven craftsman into a detail-obsessed tinkerer; b) the "venturing" trajectory can turn an entrepreneur-builder into an impulsive and careless resource waster; c) the "inventing" trajectory can transform a successful pioneer into a chaos-loving, utopian escapist; and d) the "decoupling" trajectory can change a perfect salesman into an aimless bureaucratic drifter.

All of this begs the question of what can be done to combat the threat posed by destructive leadership. Kellerman [64] puts forward 12 suggestions to strengthen a leader's capacity to be effective and ethical, two of which are organizational remedies for destructive leadership: "limiting the tenure of leadership" and "sharing power." The other 10 suggestions focus on precautions at an individual level. Similarly, Yukl [28], citing the findings of Bachman et al. [66], and Smith and Tannenbaum [67], comments that most effective organizations have a high degree of reciprocal influence. This suggests that leaders in effective organizations create relationships in which they have a strong influence over subordinates, but that they are also receptive to influence from these same subordinates. Thus, Yukl [28] concludes that leaders should facilitate reciprocal influence by encouraging subordinates to participate in important decision-making; fostering and rewarding innovation; and providing formal mechanisms to promote reciprocal influence.

Nonetheless, as valuable as all these modern views are, the most insightful remark comes from a bygone age, and from who else but Machiavelli? The goals that should be valued most, according to Machiavelli (1531), are "long-term success and the plaudits of the ages." He believed that our inability to recognize the early warning signs of corruption was the great enemy and saw "the successful prince" as one who seeks "fame for being great and excellent." The prince should achieve such fame by governing well, which means ensuring the prosperity of the state and its citizens, and creating institutions that transcend his reign, thereby securing the survival and success of the state for generations to come. 
From the perspective of this study, destructive leadership starts when a "manager + leader" stops being either a manager or leader. Hence, it is profoundly important to detect the clues and act in advance to warn, correct, or disempower destructive leaders.

\section{References}

Stogdill, R.M., Handbook of leadership: A survey of the literature, 1974. New York: Free Press.

Rost, J.C., Leadership for the twenty-first century, 1991. New York: Praeger.

Hunt, J.G., Transformational/charismatic leadership's transformation of the field: An historical essay, The Leadership Quarterly, 1999. 10(2), p. 129-144

Marion, R., and Uhl-Bien, M., Leadership in Complex Organizations, The Leadership Quarterly, 2001. 12(4), p. $389-418$

Kotter, J., A force for change: How leadership differs from management, 1990. New York: The Free Press Zaleznik, A., Managers and leaders: Are they different?, 1992. Boston: Harvard Business School Press.

Miller, D., Evolution and Revolution: A Quantum View of Structural Change in Organizations, Journal of Management Studies 1982. (Article first published at 2007). 19(8), p.131-151

Tichy, N.M., Managing strategic change: Technical, political, and cultural dynamics, 1983. New York: Wiley

Barker, R.A., How can we train leaders if we do not know what leadership is? Human Relations, 1997. 50(4), p. 343-362

Schumpeter, J.A., Development, Journal of Economic Literature, 2005.43(1), p. 108-120

Mumford, M.D., and Connelly, M.S., Leaders as creators: Leader performance and problem solving in illdefined domains. The Leadership Quarterly, 1991.2(4), p. 289-315

Scherr, A.L. and Jensen, M.C., A New Model of Leadership. 2007. Harvard NOM Research Paper No. 06-10

Kellerman, B., Bad leadership: What it is, how it happens, why it matters, 2004. Boston: Harvard Business School Press

Padilla, A., Hogan, R., and Kaiser, R.B., The toxic triangle: Destructive leaders, susceptible followers, and conducive environments, The Leadership Quarterly, 2007.18(3), p. 176-194

Einarsen, S., Aasland, M. S., and Skogstad, A., Destructive leadership behavior: A definition and conceptual model, The Leadership Quarterly, 2007. 18(3), p. 207-216

Hornstein, H.A., Brutal bosses and their prey, 1996.New York: Riverhead Books

Tepper, B.J., Consequences of abusive supervision, Academy of Management Journal, 2000.43(2), p. 178-190

Kile, S.M., Helsefarleg Leierskap. Health-endangering leadership, 1990.Universitetet i Bergen, Bergen, Norway

Ashforth, B., Petty tyranny in organizations, Human Relations, 1994. 47(7), p. 755-778

Namie, G., and Namie, R., The bully at work: What you can do to stop the hurt and reclaim the dignity on the job, 2000. Naperville: Sourcebooks, Inc.

Shackleton, V., Leaders who derail, Business Leadership, 1995. London: Thomson

Lombardo M.M., and McCall, M.W.J., Coping with an intolerable boss, 1984.North Carolina: Center for Creative Leadership

Furnham, A. and Taylor, J., The dark side of behavior at work: Understanding and avoiding employees leaving, thieving and deceiving, 2004.New York: Palgrave Macmillan

Brodsky, C.M., The Harassed Worker, 1976.Toronto: Lexington Books

Lipman-Blumen, J., The allure of toxic leaders: Why we follow destructive bosses and corrupt politicians and how we can survive them, 2005.0xford: Oxford University Press 
McCall, M.W.J., and Lombardo, M.M., Off the track: Why and how successful executives get derailed, 1983. Greensboro: Center for Creative Leadership

Shewchuk, M., Bossonomics: Destructive leadership, Canadian Operating Room Nursing Journal, 2008.26(1), p. 33-34

Yukl, G., Leadership in organizations (Sixth Edition), 2006.New Jersey: Pearson Prentice Hall

Kellerman, B., Leader-centrism: We only pay lip service to followers, Executive Excellence, 2008, 25(3), p. 5

Blake, R., and Mouton, J., The managerial grid: The key to leadership excellence, 1964. Houston: Gulf Publishing Co.

Illies, J.J., and Reiter-Palmon, R., Responding destructively in leadership situations: The role of personal values and problem construction, Journal of Business Ethics, 2008. 82(1), p. 251-272

O'Connor, J., Mumford, M.D., Clifton, T.C., Gessner, T.L., and Connelly, S.M., Charismatic leaders and destructiveness: A historiometric study, The Leadership Quarterly 1995. 6(4), p. 529-555

Schaubroeck, J., Walumbwa, F.O., Ganster, D.C., and Kepes, S., Destructive leader traits and the neutralizing influence of an "enriched" job, The Leadership Quarterly, 2007. 18(3), p. 236-251

Mumford, M.D., Gessner, T.L., Connelly, M.S., O'Connor, J.A., and Clifton, T.C., Leadership and destructive acts: Individual and situational influences, The Leadership Quarterly 1993. 4(2), p. 115-147

Mintzberg, H., Ahlstrand, B., and Lampel, J., Strategy safari. 1998. London: Pearson

Fayol, H., General and industrial management (1916), in Robbins, S.P., and Coulter, M., 2007. Management 9th Ed. New Jersey: Prentice Hall.

Robbins, S.P., and Coulter, M., 2007. Management 9th Ed. New Jersey: Prentice Hall.

Temizel, Z., 2006. Cumhuriyet Newspaper, October 2, 2006. Istanbul, Cumhuriyet Press

Ferris, G.R., Robert, Z., Brouwer, R.L., Buckley, M.R., and Harvey, M.G., Strategic bullying as a supplementary balanced perspective on destructive tendencies, The Leadership Quarterly, 2007. 18(3), p. 195-206

Mintzberg, H., Musings on management, Harvard Business Review, 1996. 74(4), p. 61-67

James, E.H., Crisis Leadership, 2004. University of Virginia Darden School Foundation, Charlottesville, VA.

Machiavelli, N., 1531. The prince and the discourses. Trans. Luigi Ricci, 1950. New York: The Modern Library,

Conger, J.A., The Dark Side of Leadership, Organizational Dynamics, 1990. 19(2), p. 44-55

Greiner, L.E., Evolution and revolution as organizations grow, Harvard Business Review, 1972. 50(4), p. 37-46

Fletcher, J.K., The paradox of post-heroic leadership: An essay on gender, power, and transformational change, The Leadership Quarterly, 2004. 15(5), p. 647-661

Beer, M., Leading learning and learning to lead in. In Conger, J., Spreitzer, G., and Lawler, E. (Eds.), The leader's change handbook, San Francisco: Jossey-Bass, 1999. p. 127-161

Meindl, J.R., Ehrlich S.B., and Dukerich, J.M., The romance of leadership, Administrative Science Quarterly, 1985. 30, p. 78-102

Rosenzweig, P., Building the civilized workplace, 2007. New York: McKinsey \& Company

Stout, L., Time for A Change, 2006. Shippensburg, PA: Destiny Image Publishers

Salancik, G.R., and Pfeffer, J... Who gets power and how they hold on to it: A strategic-contingency model of power, Organizational Dynamics, 1978. 5(3), p. 3-21

Parkinson, C. Northcote, Parkinson 's Law, 1964. New York: Ballantine Books

Schyns, B., Kroon, B., and Moors, G., Follower characteristics and the perception of leader-member exchange, Journal of Managerial Psychology, 2008. 23(7), p. 772-778 
Meyer, J.W., and Rowan, B., Institutionalized organizations: Formal structure as myth and ceremony, American Journal of Sociology, 1977. 83(2),p. 340-363

DiMaggio, P.J., and Powell, W.W., The iron cage revisited: Institutional isomorphism and collective rationality in organizational fields, American Sociological Review, 1983. 48 (April), p. 147-160

Chartrand, T.I., and Bargh, J.A., The chameleon effect: The perception-behavior link and social interaction, Journal of Personality and Social Psychology, 1999. 76, p. 893-910

Van Baaren, R.B., Holland, R.W., Kawakami, K., and Van Knippenberg, A., Mimicry and prosocial behavior, Psychological Science, 2004. 15(1), p. 71-74

Goleman, D., and Boyatzis, R., Social intelligence and the biology of leadership. 2008. Harvard Business Review. (retrieved from http://www.integraorg.com/wp-content/uploads/2014/04/Inteligencia-Social-yBiologia-de-un-Lider.pfd at June 23,2014)

Gallese, V., Fadiga, L., Fogassi, L., and Rizzolatti, G. Action recognition in the pre-motor cortex. Brain, (1996). 119 , p. 593-609.

Masterson, S. S., A trickle-down model of organizational justice: Relating employees' and customers' perceptions of and reactions to fairness. Journal of Applied Psychology, 2001. 86(4), p. 594-60

Aryee, S., Chen, Z.X., Sun, L., and Debrah, Y.A. Antecedents and outcomes of abusive supervision: Test of a trickle-down model. Journal of Applied Psychology, 2007. 92, p. 191-201

Tepper, B.J., Consequences of abusive supervision, Academy of Management Journal 2000. 43(2), p. 178-190

Hoobler, J., and Brass, D. Abusive supervision and family undermining as displaced aggression, Journal of Applied Psychology, 2006. 91, p. 1125-1133

Yamada, D.C. Crafting a legislative response to workplace bullying, Employee Rights and Responsibilities Journal, 2004. 8, p. 475-521.

Kellerman, B., Bad leadership. What it is, how it happens, why it matters, 2004. Harvard Business School Press, Boston

Baumeister, R.F., Bratslavsky, E., Finkenauer, C., and Vohs, K.E., Bad is stronger than good, Review of General Psychology, 2001. 4, p. 323-370

Bachman, J.G., Smith, C.G., and Slesinger, J.A., Control, performance and satisfaction: An analysis of structural and individual effects, Journal of Personality and Social Psychology, 1966. 4(2), p. 127-136

Smith, C.G., and Tannenbaum, A.S., Organizational control structure: A comparative analysis, Human Relations, 16(4), 1963. P. 299-316 